\title{
The effect of intradialytic exercise on inflammatory markers in hemodialysis patients
}

\author{
Howaida Abdelhameed Elshinnawy ${ }^{1}$, Mahmoud Mohamed Fayez ${ }^{1}$, Dina Abou Bakr Farrag ${ }^{2^{*}}$ and \\ Moustafa Abd Elnassier AbdElgawad ${ }^{1}$
}

\begin{abstract}
Background: Chronic low-grade inflammation is a feature of chronic kidney disease associated with increased risk of multiple morbidities and mortalities. Hemodialysis (HD) patients lead a sedentary life style which may aggravate their inflammatory state and practicing exercise may improve this condition. The aim of this work was to study the effect of intradialytic exercise (IDE) on inflammatory markers in HD patients.

Results: This prospective cohort study included 40 HD patients, divided into 2 groups: exercise group completed IDE for 3 months and non-exercise group matched in age and sex as controls. At baseline, there was no difference between both groups regarding physical performance assessed using short physical performance battery test (SPBT) or inflammatory markers C-reactive protein (CRP) and interleukin 6 (IL-6) $P>0.05$. After 3 months, SPBT significantly improved in exercise group $(P<0.001)$. Also, both serum CRP and IL-6 levels showed significant decrease in exercise group compared to baseline $(P<0.001)$, while no similar change was noticed in non-exercise group.

Conclusions: Regular intradialytic aerobic exercise program can improve physical function and inflammation in hemodialysis patients. Further studies on larger number of patients are warranted.
\end{abstract}

Keywords: Intradialytic exercise, Hemodialysis, CRP, IL-6, Albumin

\section{Background}

Chronic, low-grade inflammation is a hallmark feature of chronic kidney disease (CKD) and it is involved in the development of multiple morbidities and mortality of these patients [1]. Hemodialysis (HD) patients have elevated inflammatory marker levels, including IL-6, Creactive protein (CRP), and tumor necrosis factor- $\alpha$ which is strongly associated with increased cardiovascular mortality [2]. Many factors can affect the inflammatory state in HD patients which includes; dialysis membranes, dialysis catheters, microbial factors like gut dysbiosis, retention of uremic toxins, fluid, and sodium overload [3].

\footnotetext{
*Correspondence: dinaaboubakr@yahoo.com

2Department of Physical Medicine, Rheumatology and Rehabilitation, Faculty of Medicine, Ain Shams University, Cairo, Egypt

Full list of author information is available at the end of the article
}

Regular exercise has anti-inflammatory effect through different mechanisms including altering the balance of inflammatory cell phenotypes, decreasing inflammatory cytokine formation and visceral adipose tissue mass; it has positive influence on immune system and decrease risk of infection [4]. Yet, there is still conflict on which type of exercise could ameliorate inflammation in dialysis patients.

\section{Methods \\ Study design and participants}

This prospective cohort study was conducted on 40 endstage renal disease (ESRD) patients on regular hemodialysis 3 times/week. Patients were recruited from hemodialysis unit. Their age ranged from 22 to 65 year. The study was performed in accordance with the Declaration of the Helsinki.

\section{Springer Open}

(อ) The Author(s). 2021 Open Access This article is licensed under a Creative Commons Attribution 4.0 International License, which permits use, sharing, adaptation, distribution and reproduction in any medium or format, as long as you give appropriate credit to the original author(s) and the source, provide a link to the Creative Commons licence, and indicate if changes were made. The images or other third party material in this article are included in the article's Creative Commons licence, unless indicated otherwise in a credit line to the material. If material is not included in the article's Creative Commons licence and your intended use is not permitted by statutory regulation or exceeds the permitted use, you will need to obtain permission directly from the copyright holder. To view a copy of this licence, visit http://creativecommons.org/licenses/by/4.0/. 
Patient volunteers were equally divided and stratified according to their age and sex into two groups: the exercise group (EG) who received intradialytic exercise $(n=$ 20) and non-exercise group (NEG) acting as control group $(n=20)$ as seen in Fig. 1.

\section{Inclusion criteria}

1) Patients with ESRD on regular hemodialysis 3times/ week, for at least 1 year, session duration $4 \mathrm{~h}$, and calculated urea reduction ratio (URR) $>65 \%$

2) Age ranging from 20-70 years

3) Fit for exercise by functional assessment using 6min walk test

4) Hemoglobin level $\geq 10 \mathrm{~g} / \mathrm{dl}$

\section{Exclusion criteria}

1) Patients receiving inefficient hemodialysis

2) Unstable cardiac status (angina, decompensated congestive heart failure, uncontrolled arrhythmias)

3) Uncontrolled diabetes or hypertension

4) Patients with other cause for inflammation, e.g., malignancy, autoimmune disease, or infection

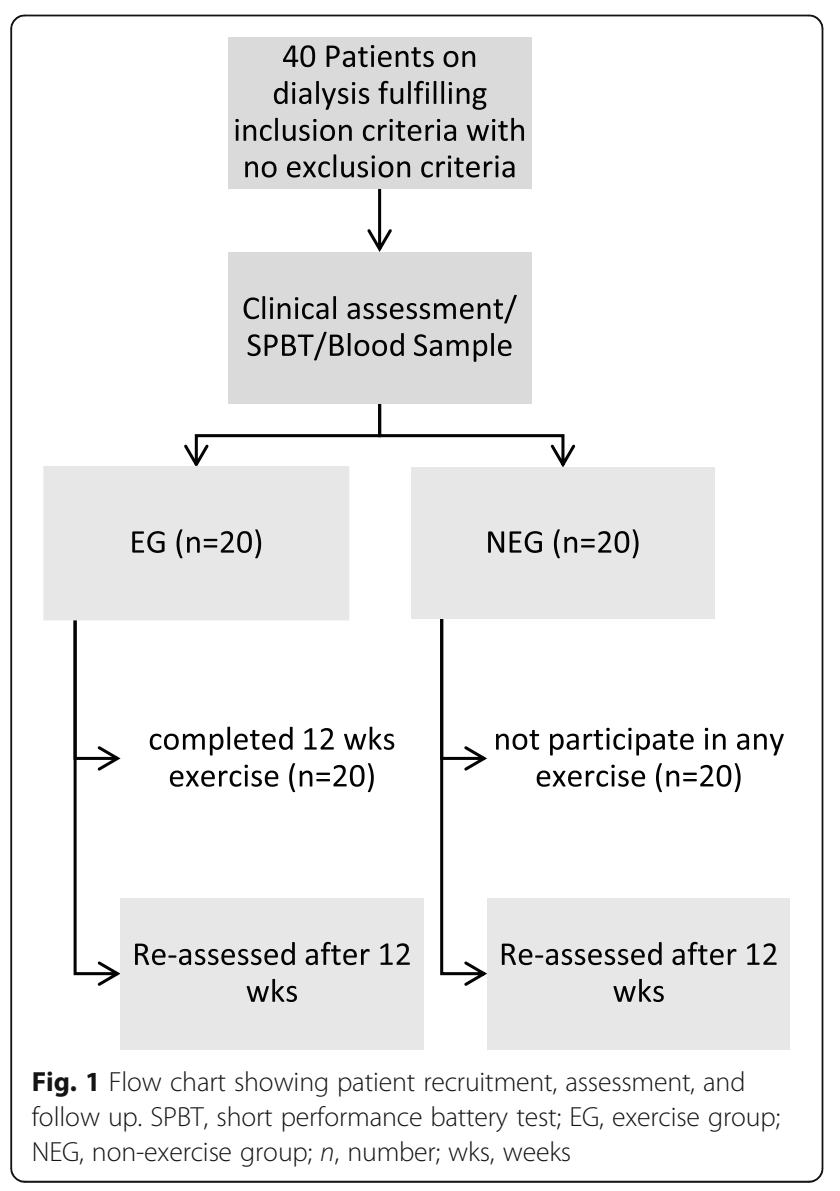

5) Physical limitations that would affect cycling. Patients with lower limb vascular access

Patients were subjected to the following:

1. Full medical history taking including personal history, etiology of ESRD, duration of hemodialysis, dialysis prescription, and comorbidities in predefined data sheets

2. Full clinical examination, including musculoskeletal and neurological examination

3. Anthropometric measures: calculation of body mass index by dividing dry body weight $(\mathrm{kg})$ by the squared height $\left(\mathrm{m}^{2}\right)$

4. Evaluation of functional performance:

a. Six-minute walk test (6 MWT): Performed indoors, along flat, straight, and enclosed corridor with a hard surface. The patient walks the distance of the corridor for $6 \mathrm{~min}$ and total distance is calculated by multiplying length of the corridor by the times the patient covered that distance [5].

b. Short physical performance battery test (SPBT): It is a short test battery, used widely in geriatrics, and assesses three components: first, patient's balance, assessing whether or not they are able to maintain their balance for at least 10 $\mathrm{s}$ with their feet together in semi-tandem and full tandem position. Second, patient's gait speed by measuring the time it takes to walk $4 \mathrm{~m}$ and third, lower extremity strength and endurance by measuring chair stand; the time it takes to sit down and stand up five times (STS5). The total score calculated by the sum of each component indicates the patient's functional state, with lowest score of 0 indicating worst function to highest score of 21 indicating best function [6].

5. Laboratory investigations

- Blood samples were collected at baseline and after 3 months of exercise program, before the mid-week session, before initiation of exercise.

- Routine investigations included blood hemoglobin, serum albumin, CRP.

- Interleukin 6: measured using enzyme linked immune sorbent assay (ELISA) based on a kit from Bioassay Technology Laboratory, Inc., Shanghai 200090, China (cat. No E0090 Hu).

- All samples were obtained on EDTA containing tube after collecting the samples, the serum was allowed to clot for 10-20 min at room temperature and then centrifugation was done (at 2000-3000 RPM) for $20 \mathrm{~min}$. Then, supernatants were collected and stored at $-80{ }^{\circ} \mathrm{C}$ for 3 months. 
Table 1 Comparison between exercise and non-exercise groups at baseline regarding demographic data, comorbidities, special habits, and functional capacity

\begin{tabular}{|c|c|c|c|c|c|}
\hline & Groups & EG $(n=20)$ & NEG $(n=20)$ & $t$ test & $P$ value \\
\hline Age, years & Mean \pm SD & $44.2 \pm 13.04$ & $47.5 \pm 9.07$ & -0.92 & 0.359 \\
\hline \multirow[t]{2}{*}{ Gender } & Females & $7(35 \%)$ & $7(35 \%)$ & $X^{2}=0.00$ & 1 \\
\hline & Males & $13(65 \%)$ & $13(65 \%)$ & & \\
\hline $\mathrm{BMI}\left(\mathrm{kg} / \mathrm{m}^{2)}\right.$ & Mean \pm SD & $26.0 \pm 3.31$ & $25.400 \pm 6.500$ & 0.398 & 0.693 \\
\hline 6-min walk (m) & Mean \pm SD & $\begin{array}{l}161.0 \pm 12.93 \\
140-180\end{array}$ & $\begin{array}{l}157.750 \pm 13.126 \\
140-180\end{array}$ & 0.789 & 0.435 \\
\hline SPBT & Mean \pm SD & $6.4 \pm 1$ & $6.5 \pm 1$ & -0.442 & 0.661 \\
\hline \multirow[t]{2}{*}{ DM } & No & $16(80 \%)$ & $14(70 \%)$ & $X^{2}=0.533$ & 0.465 \\
\hline & Yes & $4(20)$ & $6(30 \%)$ & & \\
\hline \multirow[t]{2}{*}{ HTN } & No & $9(45 \%)$ & $11(55 \%)$ & $X^{2}=400$ & 0.527 \\
\hline & Yes & $11(55 \%)$ & $9(45 \%)$ & & \\
\hline \multirow[t]{2}{*}{ Smoking status } & No & $16(80 \%)$ & $17(85 \%)$ & 0.173 & 0.677 \\
\hline & Yes & $4(20 \%)$ & $3(15 \%)$ & & \\
\hline
\end{tabular}

EG exercise group, NEG non-exercise group, independent $t$ test, $P \leq 0.05$ is significant, $B M I$ body mass index, $S P B T$ short performance battery test, $D M$ diabetes mellitus, HTN hypertension, $X^{2}$ Chi-square test, $\mathrm{kg}$ kilogram, $m$ meter

6) Exercise program: Patient education and psychological support; all patients received education on importance of exercise and physical activity, how to monitor their physical exertion, and when to stop exercise. Exercise was in the form of aerobic cycling exercise in the first $2 \mathrm{~h}$ of dialysis session using pedal exerciser that was placed in front of the patient's chair and patient pedaled while sitting upright. The NEG did not participate in any exercise. Exercise session consisted of conditioning phase first (4 weeks) in which exercise time takes 10 min cycling, a smaller number of repetitions as well as very low intensity exercise followed by progressive aerobic endurance exercise phase (8 weeks) as follows:

a. Warm-up phase (5 min): The patient started the exercise session with warm-up low intensity exercise at low speed of cycling to allow for conditioning of the body for the exercise. b. Active phase: The patient cycled for $10 \mathrm{~min}$ at the level of speed obtained at warm-up phase for 1 month (in the conditioning phase) increased gradually in the next 2 months up to 30 min, according to each patient's capability at mild to moderate intensity, provided intensity of stress as monitored on Borg Scale between 11 and 13 points [7].

c. Cooling down phase: Afterwards, the speed was decreased to low speed again and the session was terminated with cooling down for $5 \mathrm{~min}$ as in warming-up phase.

During the exercise sessions, patients were monitored for heart rate, blood pressure, and signs of fatigue. Exercise was terminated if patients develop intense physical fatigue, chest pain, dizziness, pallor, tachycardia, hypotension, or hypertension.

Table 2 Comparison between exercise and non-exercise group regarding physical performance scores and laboratory tests at baseline and after 3 months follow-up

\begin{tabular}{|c|c|c|c|c|c|c|c|c|}
\hline \multirow[b]{2}{*}{ Mean \pm SD } & \multicolumn{4}{|l|}{ Baseline } & \multicolumn{4}{|l|}{ Follow-up } \\
\hline & $\overline{\mathrm{EG}}$ & NEG & $t$ test & $P$ value & $\overline{\mathrm{EG}}$ & NEG & $t$ test & $P$ value \\
\hline$\overline{\text { SPBT }}$ & $6.4 \pm 1$ & $6.5 \pm 1$ & -0.44 & 0.661 & $7.80 \pm 1.056$ & $6.1 \pm 0.96$ & 5.307 & $<0.00^{* *}$ \\
\hline Albumin $(\mathrm{gm} / \mathrm{dl})$ & $3.9 \pm 0.2$ & $3.7 \pm 0.48$ & 1.14 & 0.260 & $4.20 \pm 0.324$ & $3.9 \pm 0.34$ & 1.984 & $0.05^{*}$ \\
\hline $\mathrm{HB}(\mathrm{gm} / \mathrm{dl})$ & $11.26 \pm 1.86$ & $11.26 \pm 1.12$ & 0.00 & 1.000 & $11.4 \pm 1.287$ & $10.9 \pm 1.38$ & 1.169 & 0.25 \\
\hline IL-6 (ng/l) & $354.2 \pm 167.1$ & $381.5 \pm 160.92$ & -0.52 & 0.602 & $251 \pm 123.4$ & $395.0 \pm 161.5$ & -3.167 & $0.003^{*}$ \\
\hline CRP (mg/l) & $8.0 \pm 1.3$ & $7.3 \pm 1.56$ & 1.41 & 0.166 & $5.3 \pm 1.309$ & $7.7 \pm 1.11$ & -10.975 & $<0.00^{* *}$ \\
\hline
\end{tabular}

EG exercise group, NEG non-exercise group, independent $t$ test, ${ }^{*} P \leq 0.05$ significant, ${ }^{* *} P \leq 0.001$ highly significant, SPBT short performance battery test, $H B$ hemoglobin, lL-6 interleukin 6, CRP C-reactive protein, gm gram, dl deciliter, $\mathrm{ng}$ nanogram, / liter, $\mathrm{mg}$ milligram 


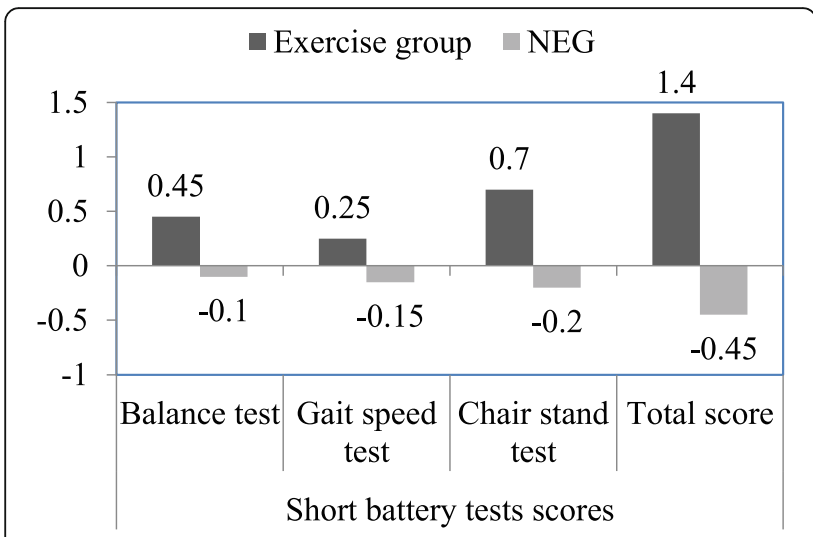

Fig. 2 Bar chart showing the change difference from baseline in SPBT total score and its components in exercise group and nonexercise group on follow up. SPBT, short performance battery test; NEG, non-exercise group

Follow-up after 3 months exercise, physical assessment using SPBT, laboratory investigations were repeated.

\section{Statistical analysis}

Recorded data were analyzed using the Statistical Package for Social Sciences, version 20.0 (SPSS Inc., Chicago, IL, USA). Quantitative data were expressed as mean \pm standard deviation (SD). Qualitative data were expressed as frequency and percentage. Independent-samples $t$ test of significance was used when comparing between two means. Mann-Whitney $U$ test for two-group comparisons in non-parametric data. Chi-square $\left(x^{2}\right)$ test of significance was used in order to compare proportions between qualitative parameters. The confidence interval was set to $95 \%$ and the margin of error accepted was set to $5 \%$. So, the probability ( $p$ value) was considered significant if $\leq 0.05$.

\section{Results}

This study showed no significant difference between EG and NEG regarding baseline demographic data, BMI, comorbid conditions like diabetes mellitus and hypertension, 6MWT, SPBT $P>0.05$ as seen in Table 1 . Regarding etiology of ESRD in the patients, diabetes and hypertension accounted for $75 \%$ of cases, $25 \%$ were due to other causes; analgesic induced nephropathy (20\%), familial (hereditary 5\%) with no significant difference between the two groups $P>0.05$. Patients received their regular treatment for diabetes and hypertension, calcium and vitamin D supplements throughout the study. As around $20 \%$ were taking beta blockers, which may slow heart rate, Borg scale was used for monitoring exercise intensity.

Also, serum albumin, blood hemoglobin, CRP, and IL6 levels at baseline were comparable at baseline between the two groups $P>0.05$ as seen in Table 2 .

In this work, all 20 patients in the exercise group completed the exercise program. The EG showed significant improvement in physical performance proved by the significant increase in the SPBT total score post exercise $P$ $<0.001$ (Table 2) and also its individual components when compared to NEG (Fig. 2).

The study showed significant decrease in inflammatory markers; CRP and IL-6 in EG after 3 months of IDE when compared to NEG $(P<0.001,<0.05$ respectively). Also, there was significant increase in serum albumin level in EG in comparison to NEG, $P=0.01$, although no difference in blood hemoglobin, as seen in Table 2.

In the exercise group, after 3 months of IDE, serum IL-6 significantly decreased from $354.2 \pm 167 \mathrm{ng} / \mathrm{l}$ to 251 $\pm 123 \mathrm{ng} / \mathrm{l}$ and CRP significantly decreased from $8.2 \pm$ $1.3 \mathrm{mg} / \mathrm{l}$ to $5.3 \pm 1.3, P<0.001$ while serum albumin significantly increased $P<0.05$ and blood hemoglobin levels increased but not to a significant level as seen in Table 3.

\section{Discussion}

Systemic inflammation in HD patients has adverse outcomes including nutritional and metabolic abnormalities with increase rate of morbidities and mortalities [8]. The participation in aerobic exercise has been recommended by the National Kidney Foundation and Kidney Disease: Improving Global Outcomes for dialysis patients [9].

This study aimed to evaluate the effect of intradialytic aerobic exercise on inflammatory markers such as CRP and IL-6 in prevalent hemodialysis patients. In this work,

Table 3 Change difference in SPBT and laboratory from baseline after completion of program in exercise group

\begin{tabular}{lllll}
\hline & $\begin{array}{l}\text { Baseline } \\
\text { Mean } \pm \text { SD }\end{array}$ & After & Mean diff & Mean \pm SD \\
\hline SPBT & $6.4 \pm 1.04$ & $7.8 \pm 1.05$ & $-1.40 \pm 0.99$ & $<0.001^{* *}$ \\
HB $(\mathrm{gm} / \mathrm{dl})$ & $11.2 \pm 1.08$ & $11.4 \pm 1.28$ & $-0.17 \pm 1.45$ & 0.608 \\
Albumin $(\mathrm{gm} / \mathrm{dl})$ & $3.9 \pm 0.24$ & $4.2 \pm 0.32$ & $-0.26 \pm 0.38$ & $0.006^{*}$ \\
CRP $(\mathrm{mg} / \mathrm{l})$ & $8.2 \pm 1.33$ & $5.3 \pm 1.309$ & $2.6 \pm 0.74$ & $<0.001^{* *}$ \\
IL-6 (ng/l) & $354.2 \pm 167.10$ & $251.0 \pm 123.40$ & $103.2 \pm 58.81$ & $<0.001^{* *}$ \\
\hline
\end{tabular}

EG exercise group, NEG non-exercise group, paired $t$ test, ${ }^{*} P \leq 0.05$ significant, ${ }^{* *} P \leq 0.001$ highly significant, $S P B T$ short performance battery test, $H B$ hemoglobin, IL-6 interleukin 6, CRP C-reactive protein, gm gram, $d /$ deciliter, $n g / l$ nanogram per liter, $m g$ milligram 
at baseline, there was no difference between patients in exercise group (EG) and non-exercise group (NEG) regarding physical performance assessed by 6 -min walk test, SPBT, or serum inflammatory markers.

The short performance battery test (SPBT) was used for following-up functional capacity in the patients as it is quick, easy to perform, and useful for monitoring change. Any variation even at one point in SPBT score has clinical significance [10]. After exercise, there was significant increase in the SPBT total score in the exercise group compared to NEG group, $P$ value $<0.001$. Also, there was significant increase in the individual components of SBPT in exercise group with no similar changes in the other group and this agrees with other studies that shows significant increase of physical performance and functional capacity of HD patients with exercise [11, 12]. The significant improvement in chair stand test in exercise group reflects an improvement in lower limb muscle strength and endurance post exercise [10].

Interlukin-6 (IL-6) is considered a strong predictor of inflammation in HD patients [3]. Although there was no difference at baseline between EG and NEG regarding serum IL-6 levels, but at follow-up there was significant difference between EG and NEG group regarding IL-6 levels, $P$ value $<0.05$. Serum IL-6 was significantly reduced from $354.2 \pm 167.10$ to $251.4 \pm$ $123.40 \mathrm{ng} / \mathrm{l}$ post-exercise, $P$ value $<0.001$. This agrees with the work of Dong et al. that showed significant decrease in IL-6 level after 12 weeks of intradialytic cycling exercise [13]. Another study showed nonsignificant effect of IDE on in IL-6 levels after 6 months of exercise which may be attributed to smaller sample size [2]. Similarly, serum CRP level significantly decreased in exercise group at 3 months follow-up, $P$ value $<0.001$ and there was significant difference between EG and NEG regarding serum CRP levels at follow-up; $P$ value $<0.001$ despite the non-significant difference between both groups at baseline. This is supported by previous work which proved that participation in intradialytic exercise reduced inflammatory markers with associated increase in physical performance [14].

According to Alves et al., higher mortality associated with low serum albumin is dependent on systemic inflammation in ESRD [15]. In this work, the exercise group at follow-up showed significant increase in serum albumin level from $3.9 \pm 0.24$ to $4.2 \pm 0.32 \mathrm{~g} / \mathrm{dl} ; P$ value $=0.05$ which may be due to improvement of nutritional and inflammatory status by exercise. Previous work by Dong et al. showed significant increase of serum albumin in dialysis patients' post-exercise [13]. However, Kato et al. found serum albumin levels increased but not to a significant effect after 1 year of resistance lower limb exercise [16].
As regards blood hemoglobin level, in our study, there was slight increase in hemoglobin levels post exercise but not reaching significant difference between the 2 groups. According to Gluba-Brzózka et al., the state of chronic low-grade inflammation could exacerbate anemia in dialysis patients influenced by inflammatory cytokines [17]. Perhaps longer duration exercise program could have shown significant improvement in hemoglobin levels post-exercise. Although the work of Chung et al. suggests positive influence of intradialytic exercise on hemoglobin level, $\mathrm{Pu}$ et al., in their systemic review, found no association between exercise and hemoglobin levels in dialysis patient $[18,19]$.

In this work, low to moderate intensity simple aerobic exercise program of few months' duration proved to ameliorate inflammation and improve physical performance in dialysis patients. The limitations of this work are not measuring dialysis efficacy using the $\mathrm{Kt} / \mathrm{V}$ formula or follow-up urea reduction ratio. However, the improvement in physical function, serum albumin, and decreased inflammatory markers indicates improved dialysis efficacy in this work. Also, the limitations of this study are the small number of patients and short duration of follow-up. Yet, future studies should focus on effect of longer duration combined aerobic, resistance, and flexibility exercise programs.

\section{Conclusions}

Intradialytic exercise improved physical performance in prevalent hemodialysis patients and significantly decreased their serum IL- 6 and CRP levels. Also, it increased serum albumin levels. Thus, low to moderate grade intra-dialytic aerobic exercise not only improved physical function but also ameliorated inflammation and contributed to the well-being of patients.

\section{Recommendations}

Hemodialysis patients should be educated regarding the beneficial effect of exercise to improve physical function, dialysis efficacy, better control of diabetes, blood pressure, improve cardiovascular function, nutrition, and mental health [20]. Health care professionals should guide, encourage, and provide facilities for patients to engage in supervised exercise programs.

\footnotetext{
Abbreviations

CRP: C-reactive protein; CKD: Chronic kidney disease; ESRD: End stage renal disease; EG: Exercise group; HD: Hemodialysis; IDE: Intradialytic exercise; 6MWT: Six-minute walk test; NEG: Non-exercise group; SPBT: Short performance battery test; IL-6: Interleukin 6; K: Dialysis clearance $[\mathrm{mL} / \mathrm{min}]$; $\mathrm{Kt} / \mathrm{V}$ : Formula to calculate dialysis session adequacy; t: Dialysis time per session [h/session]; URR: Urea reduction ratio; V: Body fluid volume [mL]
} 


\section{Authors' contributions}

HE: main idea, revised paper; MF: collect clinical data, data analysis, write paper; DF: study design, follow up patients, editing paper; MA: clinical supervision, data analysis, editing paper. All authors have read and approved the manuscript.

\section{Funding}

This study had no funding from any resource.

\section{Availability of data and materials}

The datasets used and/or analyzed during the current study are available from the corresponding author on reasonable request.

\section{Declarations}

\section{Ethics approval and consent to participate}

The study was performed in accordance with the Declaration of the Helsinki. It was approved by the Ethics Committee of Faculty of Medicine, Ain Shams University, approval number MS275/2020. This study was conducted from June 2020 to September 2020; each participant signed a written informed consent.

\section{Consent for publication}

Not applicable.

\section{Competing interests}

The authors declare that they have no competing interests.

\section{Author details}

'Department of Internal Medicine and Nephrology, Faculty of Medicine, Ain Shams University, Cairo, Egypt. ${ }^{2}$ Department of Physical Medicine, Rheumatology and Rehabilitation, Faculty of Medicine, Ain Shams University, Cairo, Egypt.

Received: 17 July 2021 Accepted: 29 August 2021

Published online: 30 November 2021

\section{References}

1. Mihai S, Codrici E, Popescu ID, Enciu AM, Albulescu L, Necula L et al (2018) Inflammation-related mechanisms in chronic kidney disease prediction, progression, and outcome. Journal of immunology research 2018:21803732180316. https://doi.org/10.1155/2018/2180373

2. Dungey M, Young H, Churchward DR, Burton JO, Smith AC, Bishop NC (2017) Regular exercise during haemodialysis promotes an antiinflammatory leucocyte profile. Clinical kidney journal 10(6):813-821. https:// doi.org/10.1093/ckj/sfx015

3. Cobo G, Lindholm B, Stenvinkel P (2018) Chronic inflammation in end-stage renal disease and dialysis. Nephrology Dialysis Transplantation 33(3):iii35iiii40. https://doi.org/10.1093/ndt/gfy175

4. Suzuki K (2019) Chronic inflammation as an immunological abnormality and effectiveness of exercise. Biomolecules 9(6):223. https://doi.org/10.3390/ biom 9060223

5. Du H, Newton PJ, Salamonson Y, Carrieri-Kohlman VL, Davidson PM (2009) A review of the six-minute walk test: its implication as a self-administered assessment tool. European journal of cardiovascular nursing 8(1):2-8. https://doi.org/10.1016/..ejcnurse.2008.07.001

6. Guralnik JM, Simonsick EM, Ferrucci L, Glynn RJ, Berkman LF, Blazer DG, Scherr PA, Wallace RB (1994) A short physical performance battery assessing lower extremity function; association with self-reported disability and prediction of mortality. J Gerontol 49(2):M85-M94. https://doi.org/10.1093/ geronj/49.2.M85

7. Borg GA (1982) Psychophysical bases of perceived exertion. Med Sci SportsExerc 14(5):377-381. https://doi.org/10.1249/00005768-19820500000012

8. Jankowska M, Cobo G, Lindholm B, Stenvinkel P (2017) Inflammation and protein-energy wasting in the uremic milieu. Contrib Nephrol 191:58-71. https://doi.org/10.1159/000479256

9. Mallamaci F, Pisano A, Tripepi G (2020) Physical activity in chronic kidney disease and the EXerCise Introduction To Enhance trial. Nephrology, dialysis, transplantation 35(Suppl 2):ii18-ii22. https://doi.org/10.1093/ndt/gfaa012
10. Nogueira A, Álvarez G, Russo F, San-José B, Sánchez-Tomero JA, Barril G (2019) Is SPPB useful as a method for screening functional capacity in patients with advanced chronic kidney disease? Nefrología 39(5):489-496. https://doi.org/10.1016/.nefroe.2019.01.010

11. Abou El-Saoud A, Shehata O, Emerah A, Sayed E (2014) Evaluation of exercise training on work capacity, functional mobility and quality of life in hemodialysis patients. Egypt Rheumatol Rehabil 41(3):103-108. https://doi. org/10.4103/1110-161X.140524

12. Lopes LC, Mota JF, Prestes J, Schincaglia RM, Silva DM, Queiroz NP et al (2019) Intradialytic resistance training improves functional capacity and lean mass gain in individuals on hemodialysis: a randomized pilot trial. Arch Phys Med Rehabil 100(11):2151-2158. https://doi.org/10.1016/j.apmr.2019.06.006

13. Dong ZJ, Zhang HL, Yin LX (2019) Effects of intradialytic resistance exercise on systemic inflammation in maintenance hemodialysis patients with sarcopenia: a randomized controlled trial. Int Urol Nephrol 51(8):1415-1424. https://doi.org/10.1007/s11255-019-02200-7 Epub 2019 Jul 3. PMID: 31270740; PMCID: PMC6660503

14. Sovatzidis A, Chatzinikolaou A, Fatouros IG, Panagoutsos S, Draganidis D, Nikolaidou E, Avloniti A, Michailidis Y, Mantzouridis I, Batrakoulis A, Pasadakis P, Vargemezis V (2020) Intradialytic cardiovascular exercise training alters redox status, reduces inflammation and improves physical performance in patients with chronic kidney disease. Antioxidants 9(9):868. https://doi.org/1 0.3390/antiox9090868

15. Alves FC, Sun J, Qureshi AR, Dai L, Snaedal S, Bárány P, Heimbürger O, Lindholm B, Stenvinkel P (2018) The higher mortality associated with low serum albumin is dependent on systemic inflammation in end-stage kidney disease. PLoS One 13(1):e0190410. https://doi.org/10.1371/journal.pone.01 90410

16. Kato M, Shibata M, Asai K, Harada K, Ito I, Tawada H, Nagai K, Taniguchi S (2021) One-year intradialytic leg exercises with resistance bands and fat mass increase in elderly hemodialysis patients: a retrospective study. Ren Replace Ther 7(1):21. https://doi.org/10.1186/s41100-021-00341-z

17. Gluba-Brzózka A, Franczyk B, Olszewski R, Rysz J (2020) The influence of inflammation on anemia in CKD patients. International journal of molecular sciences 21(3):725. https://doi.org/10.3390/ijms21030725

18. Chung YC, Yeh ML, Liu YM (2017) Effects of intradialytic exercise on the physical function, depression and quality of life for hemodialysis patients: a systematic review and meta-analysis of randomized controlled trials. J Clin Nurs 26(13-14):1801-1813. https://doi.org/10.1111/jocn.13514

19. Pu J, Jiang Z, Wu W, Li L, Zhang L, Li Y, Liu Q, Ou S (2019) Efficacy and safety of intradialytic exercise in hemodialysis patients: a systematic review and meta-analysis. BMJ Open 9(1):e020633. https://doi.org/10.1136/ bmjopen-2017-020633

20. Ghafourifard M, Mehrizade B, Hassankhani H, Heidari M (2021) Hemodialysis patients perceived exercise benefits and barriers: the association with health-related quality of life. BMC Nephrol 22(1):94. https://doi.org/10.1186/ s12882-021-02292-3

\section{Publisher's Note}

Springer Nature remains neutral with regard to jurisdictional claims in published maps and institutional affiliations.

\section{Submit your manuscript to a SpringerOpen ${ }^{\circ}$ journal and benefit from:}

- Convenient online submission

- Rigorous peer review

- Open access: articles freely available online

- High visibility within the field

- Retaining the copyright to your article

Submit your next manuscript at $\boldsymbol{\nabla}$ springeropen.com 